\title{
Hyperbolic Medicine: General and Local Hyperbolic Curves on Earth, Influencing Human Physiology
}

\author{
Jesús M. González-González
}

\author{
Doctor of Medicine and Surgery (University of Alicante), Specialist in Stomatology \\ (University of Murcia), Practice in a Private Dental Clinic, in Salamanca (Spain)
}

\author{
*Corresponding author details: Dr. Jesús M. González-González; gongonjm@hotmail.com
}

\begin{abstract}
The objective of this work is to study the hyperbolic space-time curves that we perceive in our daily lives through images obtained in different geographical locations on Earth. A bibliographic review of scientific works has been made on hyperbolic curves in medicine, electromagnetic fields, circadian rhythms, and space-time perpendicular to the movement of an organ. On the internet, images in conical perspective have been selected, of cities located at different longitudes and latitudes within the geography of the Earth. They have tried to identify hyperbolic space-time curves. They have then been compared with the hyperbolic curves of the Earth's magnetic field. Finally, we determine its relationship with the hyperbolic curves of human physiology. We have as conclusions: 1. Human vision is hyperbolic because the space in which we live is deformed by "general hyperbolic curves" that exist at any longitude and latitude of the earth's geography. 2 . The lines of force of the Earth's magnetic field are hyperbolas that follow "local hyperbolic curves" since they can vary in intensity and even reverse their polarity over time. 3. In the physiology of the human body there are hyperbolic curves that are similar to the lines of force of a magnet and the magnetic field of the Earth. Human physiology can be conditioned by general hyperbolic curves and by local hyperbolic curves. There is an adaptation to that hyperbolic deformation of the space in which we live.
\end{abstract}

Keywords: synchronization; hyperbolic; medicine; space; time; magnetic; physiology; human; relativity

\section{INTRODUCTION}

A hyperbolic curve is an open geometric figure with two branches, obtained by cutting a right cone along a plane oblique to the axis of symmetry. The plane does not have to be parallel to the axis of the cone and the hyperbola will be symmetric in any case [1].

We call "Hyperbolic Medicine" (abbreviated "Medipérbola") to the study of hyperbolic curves that occur in the physiology of a living being, especially in humans, about other hyperbolic curves that may be in nature, such as electromagnetic fields, expansion-contraction systems in motion, circadian rhythms, and space-time relativity.

It has been described that the human eye perceives the space around us as a hyperbola [2]. Hyperbolic curves are very common in human physiology $[3,4]$. In nature, there are also hyperbolic curves as in human physiology. The Earth's magnetic field has lines of force that follow a hyperbolic pattern. In a simple magnet, lines of force similar to those of the Earth's magnetic field have also been described $[5,6]$. According to previous studies, the closest houses are perceived as larger than those further away. The image of each house is transferred to the human eye at the speed of light. However, the path of this image to the observer's eye does not go in a straight line, but through a curved line that is similar to the lines of force in a magnetic field [3,4,7-9]. Images of nature are hyperbolic because the warped space in which we live is hyperbolic (figure 1).

A space-time relativity perpendicular to the axis of motion of an organ has also been described. According to the Theory of Relativity, an object that moves on an X-axis perpendicular to the line of sight of an observer contract that length $\mathrm{X}$ and its time is dilated, while its dimensions $\mathrm{Y}$ and $\mathrm{Z}$ perpendicular to said direction of movement is not altered $[10,11]$. According to current works, it is different if that object moves perpendicular to the line of sight of an observer, or if it approaches or moves away in the same line of sight [3,4,7-9]. These works indicate that when the object approaches an observer in the same line of sight, he perceives its height $(\mathrm{Y})$ and width $(\mathrm{Z})$ increasing in size. For that reason he interprets that these dimensions $\mathrm{Y}$ and $\mathrm{Z}$, perpendicular to the axis of movement of the object, have been dilated. If the object moves away from the observer along the same line of sight, the observer perceives those dimensions $\mathrm{Y}$ and $\mathrm{Z}$, perpendicular to the movement, each time smaller, for which he interprets that there is a contraction [3,4,7-9] (table 1) (figure 2).

In both cases, the observer perceives hyperbolic images, when the organ approaches or when it moves away. The expansion factor perpendicular to the movement $\mathrm{K}=1 / \sqrt{1}$ $\mathrm{v}^{2} / \mathrm{c}^{2}$ calculated in previous works [7], if we transform it into $1 / \mathrm{K}^{2}=1-\mathrm{v}^{2} / \mathrm{c}^{2}$ it gives us the hyperbola in approximation [3]. The contraction factor perpendicular to the movement

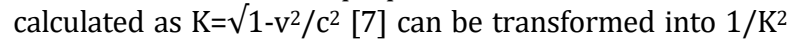
$=1-\mathrm{c}^{2} / \mathrm{v}^{2}$, which is the hyperbola in distancing [3].

It has been pointed out that when an organ moves away from the observer it does so according to the hyperbolic lines of force that enter through the south pole of a magnet. When the organ approaches an observer, it does so according to the hyperbolic lines of force that emerge from the north pole of a magnet. For a better understanding, in previous works this space has been fragmented into two parts: in the first, a human organ (heart) moves away from 
the observer according to the hyperbolic lines of force that enter through the south pole of a magnet and into a second part, the human organ (heart) approaches the observer according to hyperbolic lines of force that emerge from the north pole of a magnet [3] (figure 3).

Several authors point out that electromagnetic fields have effects on human physiology [12-15]. On the other hand, biological rhythms are repeated over time and are related to the rotation of the Earth on its axis and around the Sun [16]. Time and the rhythms of the biological clock have been thought to be in the genetic code. These are regulated by environmental signals (light, temperature, humidity, rest, sound) and are synchronized to approach the stimulus frequency $[16,17]$. These human circadian rhythms can follow hyperbolic curves $[18,19]$.

We think that the hyperbolic curves that occur in human physiology may be related to those that occur in nature, and the latter may be different depending on the geographical place on Earth where they are studied.

The objective of this work is to study the hyperbolic spacetime curves that we perceive in our daily lives through images obtained in different geographical locations on Earth. And then establish its relationship with the hyperbolic curves of the Earth's magnetic field and those that occur in human physiology.

\section{MATERIAL AND METHODS}

In Internet search engines, and in various databases (Medline, Scielo) a bibliographic review of scientific works has been made on hyperbolic curves in medicine, electromagnetic fields, circadian rhythms, and space-time perpendicular to the movement of an organ. On the internet, images in conical perspective have been selected, of cities located at different longitudes and latitudes within the geography of the Earth. The chosen images are free to use, share and adapt (Wikimedia commons, CCO 1.0 Universal Public Domain Dedication, Attribution 3.0 Unported, Attribution ShareAlike 3.0 Unported) [20-41]. They have tried to identify hyperbolic space-time curves (Fig. 4). They have then been compared with the hyperbolic curves of the Earth's magnetic field. Finally, we determine its relationship with the hyperbolic curves of human physiology.

\section{RESULTS}

1) There is a space-time relativity perpendicular to the axis of movement of an organ that gives hyperbolic curves [3,4,7-9] (table 1) (figure 2).

2) Images in nature are "general hyperbolas" and exist independently of the longitude and latitude of the Earth where they are observed. The lines of force in the Earth's magnetic field are "local hyperbolas," which may not coincide with the general hyperbolic curves noted above.

3) Electromagnetic fields have effects on human physiology [12-15] (table 2) and act through local hyperbolic curves, that is, those generated by the electromagnetic field itself. In human physiology, hyperbolic curves are very frequent (table 3) [2-4,42-55] and can be influenced by general and local hyperbolic curves.

4) Human circadian rhythms can be synchronized with the hyperbolic curves that occur in nature $[18,19]$, through general and local hyperbolic curves.

\section{DISCUSSION}

At the Earth's equator (zero latitudes) we have the cities of Quito and Nairobi. The two are at very different land lengths, but in images of those cities, we see conical perspectives, representing hyperbolic curves of space-time. Within the Arctic Circle (latitude 66 33’52” N), also in different terrestrial longitudes, we have the cities of Toms $\varnothing$ and Norilsk. In both, we see images of conical perspectives.
The Antarctic Circle has a latitude of 66 $33^{\prime} 46^{\prime \prime}$ S. If we look at an image of McMurdo Station, in Antarctica, we also see a conical perspective. In the images of all the cities studied, at different latitudes and longitudes, there are conical perspectives (fig. 4). A conical perspective image is a static image. It is a snapshot image. When we see that moving image, the lines turn into curves and we see a hyperbola. In all the images studied there are hyperbolic curves and they occur at any longitude and latitude of the Earth's geography. We can call them "general hyperbolic curves".

On the other hand, we know that the Earth's magnetic field has lines of force that are also hyperbolic curves, but they can vary with time and even reverse their polarity. For this reason, they must be considered "local hyperbolic curves". It is known that the Earth's magnetic field has been reversed on multiple occasions, at different geological times [56]. This field is different at the poles than it is at the Earth's equator. At the poles it gives a receding hyperbolic image, however, at the Earth's equator, the inclination of the magnetic field is zero, as it is parallel to the Earth's surface [57].

Some time ago, this same author considered that the hyperbolic images that we perceive of reality were caused by the hyperbolic magnetic lines of the Earth's magnetic field, but according to the results of this work, they cannot be so. The hyperbolic curves that occur in any longitude and latitude of the terrestrial geography are there, they are independent of other circumstances and therefore they are "general hyperbolic curves". In contrast, the Earth's magnetic field generates "local hyperbolic curves", which can vary over time and even reverse their polarity.

The results obtained indicate that hyperbolic curves are very common in medicine and are found in many human physiological processes [42-55]. It is possible to think that human physiology is conditioned by that deformed space in which we live. In this way, the hyperbolic curves that we see in medicine could be related to this hyperbolic deformation. Some hyperbolic curves that occur in human physiology may be conditioned by the local hyperbolic curves of the Earth's magnetic field. But there may also be an adaptation of human physiology to the general hyperbolic deformation of the space in which we live.

Geomagnetic rhythms can act as a time clock to organize physiological rhythms. This means that human biorhythms follow hyperbolic curves, synchronized with the local hyperbolic lines of the Earth's magnetic field. If external stimuli are applied that modify the hyperbolic physiological curves, these tend to synchronize again to become hyperbolas again. Cellular physiological processes are subject to permanent synchronization [19]. The cells of the human body synchronize their physiological processes to create similar hyperbolic curves. There is a close interaction between geomagnetic and biomagnetic fields throughout evolution [12-19]. There may be a "long life biorhythm", ranging from birth to death. At birth, this "longlived biorhythm" appears in cellular physiology and becomes hyperbolic by synchronizing with the local hyperbolic lines of force of the Earth's magnetic field. We assume that the general hyperbolic curves influence this synchronization [19].

\section{CONCLUSIONS}

1) Human vision is hyperbolic because the space in which we live is deformed by "general hyperbolic curves" that exist at any longitude and latitude of the earth's geography. 2) The lines of force of the Earth's magnetic field are hyperbolas that follow "local hyperbolic curves" since they can vary in intensity and even reverse their polarity over time. 
3) In the physiology of the human body there are hyperbolic curves that are similar to the lines of force of a magnet and the magnetic field of the Earth. Human physiology can be conditioned by general hyperbolic curves and by local hyperbolic curves. There is an adaptation to that hyperbolic deformation of the space in which we live.

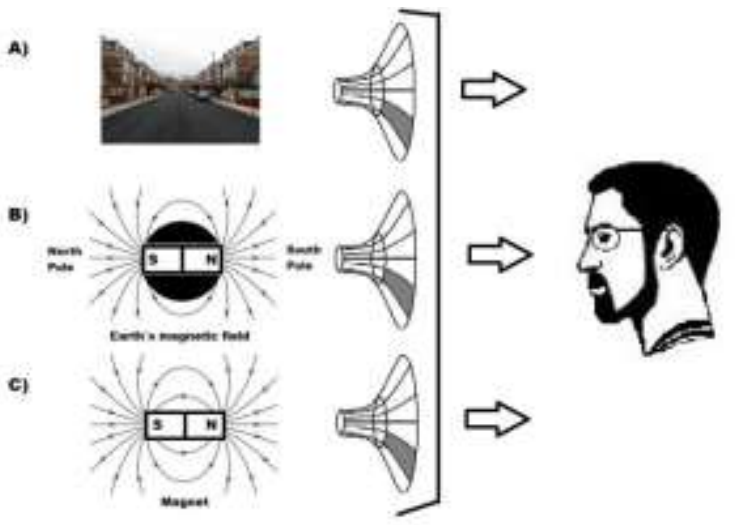

FIGURE 1: The houses farthest from the observer are smaller for him because he sees a hyperbolic image (A). When an observer sees the Earth's magnetic field, the lines of force are also hyperbolic (B). The same happens with the pole of a magnet (C).

TABLE 1: The classical theory of relativity and the results of a previous study by the author.

\begin{tabular}{|c|c|}
\hline \multirow{2}{*}{$\begin{array}{l}\text { Classical theory of } \\
\text { Relativity. Objact } \\
\text { moves perpendicular to } \\
\text { the observer's lne of } \\
\text { sight }\end{array}$} & $\begin{array}{l}\text { Length } X \text { parallel to the axis of movemeat contracts by a } \\
\text { factor } K=\sqrt{1-v^{2} / c^{2}}\end{array}$ \\
\hline & $\begin{array}{l}\text { Time } \mathrm{t}_{\mathrm{a}} \text { paralld to the axis of movement dilates by a } \\
\text { factor } \mathrm{K}=\frac{1}{\sqrt{2 \cdot v^{2} / \mathrm{e}^{2}}}\end{array}$ \\
\hline \multirow[b]{2}{*}{$\begin{array}{l}\text { Results of a previous } \\
\text { study by the arthor. } \\
\text { Object approaches of } \\
\text { moves anayy from the } \\
\text { observer in his sane } \\
\text { line of sight }\end{array}$} & $\begin{array}{l}\text { Lengths } Y \text { and } Z \text { perpendicular to the axis of movemient; } \\
\text { - When the organ approeshes the observer these lengths } \\
\text { dilate by afacter } K=\frac{1}{\sqrt{1-v^{2} / c^{2}}} \\
\text { - When the organ moves away from the observer these } \\
\text { lengths contract by a factor } K=\sqrt{1-v^{2} / c^{2}}\end{array}$ \\
\hline & $\begin{array}{l}\text { Times } \mathrm{t}_{\mathrm{f}} \text { and } \mathrm{t} \text { papendicular to the axis of movement: } \\
\text { - When the organ approaches the observer these times } \\
\text { contract by a factor } \mathrm{K}=\sqrt{1-\mathrm{v}^{2} / \mathrm{c}^{2}} \\
\text { - When the organ moves away from the observer these } \\
\text { times dilate by a factar } \mathrm{K}=\frac{1}{\sqrt{1-+^{1} / \mathrm{e}^{2}}}\end{array}$ \\
\hline
\end{tabular}
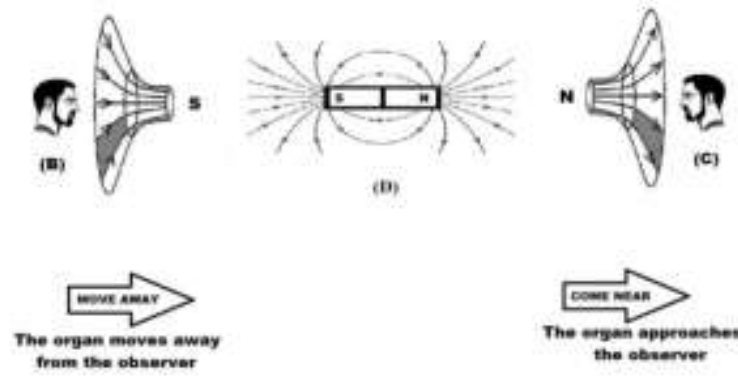

(b)
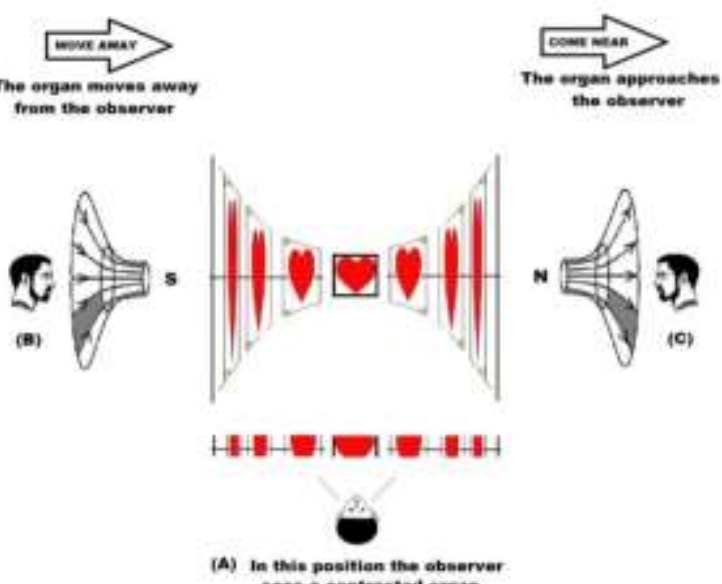

(A) In this positian the observer
FIGURE 2: When an organ moves perpendicular to the observer's line of sight, he sees it contracted (A). If the organ is moving parallel to its line of sight, the observer sees a hyperbola moving away (B) or approaching (C). This is similar to the lines of force of the magnetic field (D). When this organ moves away from the observer, it follows the hyperbolic lines of force that enter through the south pole of the magnet (B). If that organ gets closer, it follows the hyperbolic lines of force coming out of the north pole of the magnet (C).

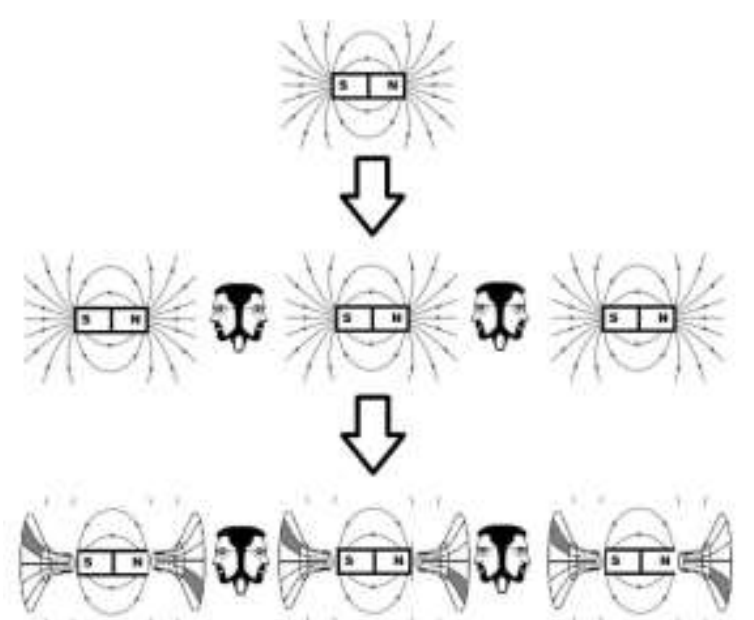

FIGURE 3: If we divide a magnet into several fragments, we obtain similar magnets. If we place an observer in the middle of these fragments, the hyperbolic lines of force approach the observer from the north pole N, while those hyperbolic lines of force move away from the observer towards the south pole $\mathrm{S}$.
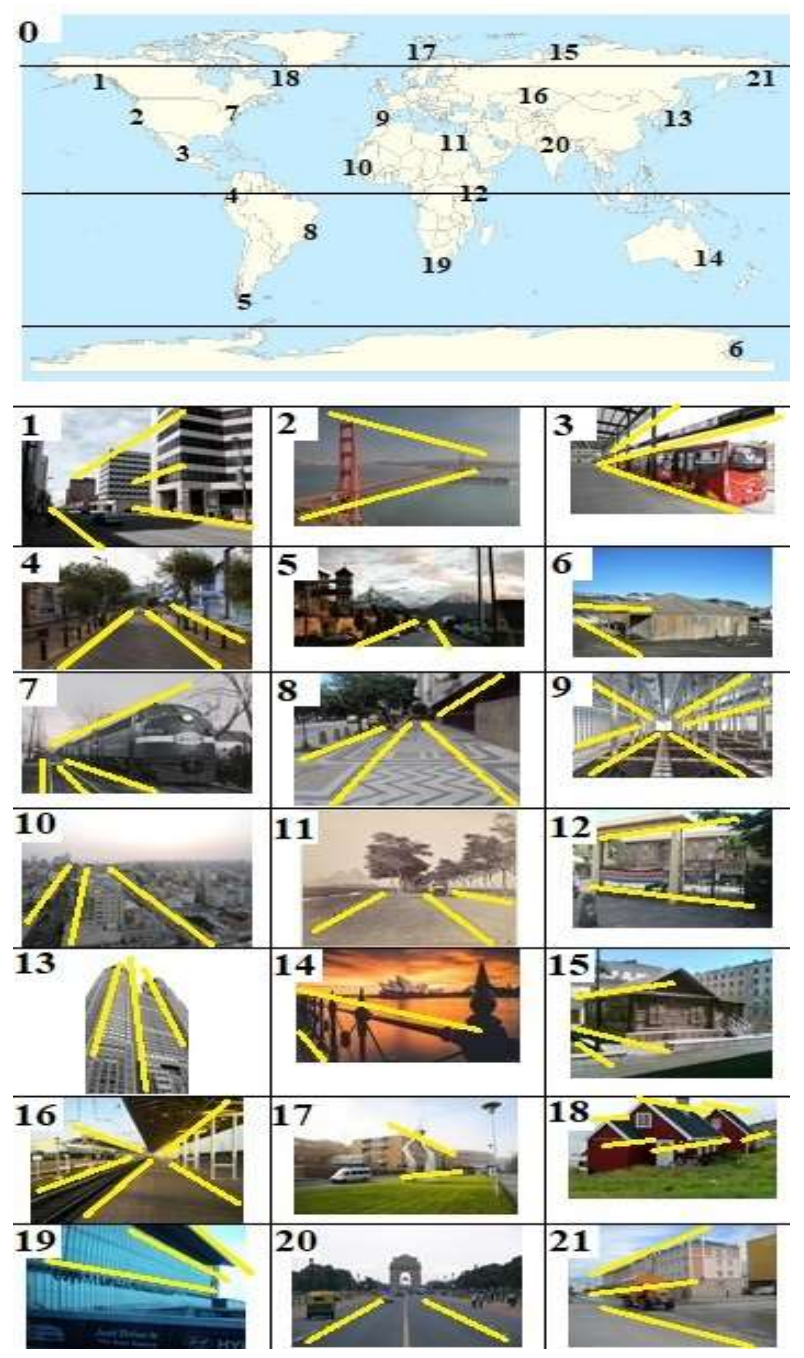
FIGURE 4: Hyperbolic curves marked in yellow on images of cities located at different longitudes and latitudes of the Earth. 0 Worldwide distribution [20]. 1 Anchorage [21]. 2 San Francisco [22]. 3 Mexico City [23]. 4 Quito [24]. 5 Ushuaia [25]. 6 McMurdo Station [26]. 7 New York [27]. 8 Rio de Janeiro [28]. 9 Madrid [29]. 10 Dakar [30]. 11 Cairo [31]. 12 Nairobi [32]. 13 Tokyo [33]. 14 Sidney [34]. 15 Norilsk [35]. 16 Astana [36]. 17 Troms $\varnothing$ [37]. 18 Nuuk [38]. 19 Cape Town [39]. 20 New Delhi [40]. 21 Anadyr [41].

TABLE 2: Effects of electromagnetic fields on human physiology

- There are effects on nerves, heart tissue, skeletal muscle, and other body tissues.

- Some cells move towards the cathode (fibroblasts, keratinocytes, chondrocytes, epithelial cells) and others towards the anode (corneal endothelial cells, granulocytes, vascular endothelial cells], but this depends on the animal species.

- Some molecules produce permanent dipoles that align with the applied electric field.

- Channels and ion receptors in the cell membrane can be altered by modifying the activation kinetics.

-Electromagnetic fields can regulate the speed and quantity of products of biochemical reactions.

-Also the magnetic field of the Earth influences the geomagnetic orientation and navigation of some fish, migratory birds, butterflies, and bees.

TABLE 3: Hyperbolic curves in physiology.

\begin{tabular}{l}
\hline - Oxygen saturation for hemoglobin and myoglobin about \\
partial oxygen pressure \\
- Sometimes dose-effect relationship curves \\
- Glucokinase and fructokinase saturation curves \\
- Aspartate saturation curves \\
- Insulin sensitivity in oral glucose tolerance test \\
- Heart rate responses during exercise \\
- Strength-speed ratio of myocardial myosin isoenzymes \\
- Force-speed ratio of shortening of skeletal muscle fibers \\
- In aviation, periods of incapacitation in extreme gravitational \\
stress \\
- Descriptions of the perception of odors, in an olfactory space \\
- The human eye perceives a hyperbolic image of reality \\
\hline
\end{tabular}

\section{CONFLICT OF INTEREST}

The author reported no conflicts of interest related to this study.

\section{REFERENCES}

[1] Chambadal L. (1984). Diccionario de matemáticas. Barcelona: Ediciones Grijalbo, S.A.

[2] Gómez Argelles J. (2016). Cuando las rectas se vuelven curvas. Las geometrías no euclídeas. Barcelona: Ed. RBA Coleccionables.

[3] González-González, JM. (2020). Hyperbolic curves in Medicine and the Earth's magnetic field. International Journal of Science and Research (IJSR), 9(3), 16201624.

[4] González-González JM. (2020). Hyperbolic Medicine. A Space-Time Synchronization External to the Human. International Journal of Science and Research (IJSR), 9 (11), 234-239.

[5] Garcia Santemases, J. (1078). Física general. Octava edición. Madrid: Ed. Paraninfo.

[6] Halliday D, Resnick R. Física. (1990). Parte 2. Mexico: Compañía Editorial Continental, S.A.
[7] González-González JM. (2017). Teleportation of human and their organs in the treatment of cancer. International Journal of Current Research, 9(6), 52659-52663.

[8] González-González JM. (2017). Teleportation of human organs in the treatment of diseases, hyperbolic spaces and unified fields. International Journal of Current Research, 9(9), 57340-57342.

[9] González-González, JM. (2019). Physical Theory of Premonition in Medicine. International Journal of Science and Research (IJSR), 8(5), 1340-1344.

[10] Resnick R. (1981). Introducción a la teoría especial de la relatividad. Mexico: editorial Limusa,

[11] Andreu Tormo J. (1978). La relatividad descifrada. Valencia: Industrias Gráficas ECIR.

[12] Valentinuzzi ME. (2004). Magnetobiology: a historical view. IEEE Eng Med Biol Mag, 23(3), 85-94.

[13] Sachiko Yamaguchi-Sekino, Masaki Sekino, Shoogo Ueno. (2011). Biological effects of electromagnetic fields and recently updated safety guidelines for strong static magnetic fields. Magn Reson Med Sci, 10(1), 1-10.

[14] Richard H W Funk, Thomas Monsees, Nurdan Ozkucur. (2009). Electromagnetic effects - From cell biology to medicine. Prog Histochem Cytochem, 43(4), 177-264.

[15] Zannella S. Biological effects of magnetic fields. Accessed September 10, 2020 at https://cds.cern.ch/record/1246526/files/p375.pdf.

[16] Barcia Salorio, D. (2007). Ritmos biológicos y periodicidad en psiquiatría. Murcia: Cuaderna editorial.

[17] Rojo Sierra, M. (1984). La asimetría cerebral y la experiencia psicológica y patológica del tiempo. Valencia: Sancho Artes Gráficas.

[18] González-González, JM. (2018). Circadian rhythms and dental caries. International Journal of Current Research, 10(7), 71616-71618.

[19] González-González, JM. (2020). Psychological and physiological time, in childhood and old age. Synchronization with the Earth's hyperbolic magnetic field. EAS J Med Surg, 2(6), 140-145.

[20] Gringer. World map (equirectangular projection, 1:50m resolution) Made with public domain data from Natural Earth. Public domain. Accessed August 1,2021 at https://commons.wikimedia.org/wiki/File:NED_wor ldmap_110m.svg

[21] Warren LeMay. Downtown, Anchorage, AK along W 5th Ave. Creative Commons Zero, Public Domain Dedication. Creative Commons Attribution-Share Alike 4.0. No restrictions. Accessed July 25, 2021 at https://commons.wikimedia.org/wiki/File:Downto wn,_Anchorage,_AK_along_W_5th_Ave.jpg

[22] Dsdugan. Golden Gate Bridge. Creative Commons Zero, Public Domain Dedication. No restrictions. Accessed July 25, 2021 at https://commons.wikimedia.org/wiki/File:17_31_0 59_bridge.jpg 
[23] Gobierno CDMX. Transporte público de la Ciudad de México. Autobuses, metrobús, metro. Creative Commons Zero, Public Domain Dedication. No restrictions. Accessed July 25, 2021 at https://commons.wikimedia.org/wiki/File:Transpor te_p\%C3\%BAblico_de_la_Ciudad_de_M\%C3\%A9xico_ IMG_1005_(26911176681).jpg

[24] Sebastian Reategui. View of the street José Calama, in the suburb of Mariscal Sucre, Quito, Ecuador. Creative Commons Zero, Public Domain Dedication. Accessed August 1, 2021 at

https://commons.wikimedia.org/wiki/File:La_calle_J os\%C3\%A9_Calama_en_Mariscal_Sucre,_Quito,_Ecua dor_01.jpg

[25] Moncay at German Wikipedia. Ushuaia, Feuerland/Argentinien. Public domain. Accessed July 25,2021 at

https://commons.wikimedia.org/wiki/File:Ushuaia.j pg

[26] Emilio floris, member of the english Wikipedia. Hut remaining from the Discovery expedition with McMurdo Station in the background. Public domain. Accessed July 25, 2021 at https://commons.wikimedia.org/wiki/File:Scott_hut _mcmurdo.jpg

[27] Railfan 44. A Roger Puta Photograph. Public domain. Accessed July 27, 2021 at https://commons.wikimedia.org/wiki/File:NYC_169 6_(F7A)_the_old_Peoria_and_Eastern_Railway,_Bloo mington,_IL_in_April_1965_(21879890083).jpg

[28] [28] Eduardo P. Street of Botafogo Beach, Rio de Janeiro city, Brazil. Public domain. Accessed July 27 2021 at

https://commons.wikimedia.org/wiki/File:Praia_de_ Botafogo_2.JPG

[29] Farrokh_Bulsara a.k.a. Carlos Bonilla. Interior de la estación Puerta de Atocha, Madrid. Creative Commons Zero, Public Domain Dedication. Accessed July 27, 2021 at

https://commons.wikimedia.org/wiki/File:Interior_ of_Atocha_railway_station.jpg

[30] (WT-en) Kahuna613 at English Wikivoyage. Sunset from Hotel de l'Independance. Public domain. Accessed July 27, 2021 at https://commons.wikimedia.org/wiki/File:Senegal_ 141.jpg

[31] Félix Bonfils. Caire. Allée de Pyramides. Creative Commons Zero, Public Domain Dedication. Accessed August 1, 2021 at https://commons.wikimedia.org/wiki/File:Caire._All \%C3\%A9e_de_Pyramides_MET_DP113870.jpg

[32] Kriddl. Supreme Court of Kenya in Nairobi at December 12 2011. Creative Commons Zero, Public Domain Dedication. Accessed August 1, 2021 at https://commons.wikimedia.org/wiki/File:Supreme _Court_of_Kenya.JPG

[33] Dinomanía2020. Tokyo Metropolitan Government Building, Tokyo,Japan. Creative Commons Zero, Public Domain Dedication. Accessed August 1, 2021 at https://commons.wikimedia.org/wiki/File:Edificio_ del_Ayuntamiento_de_Tokio,_Jap\%C3\%B3n.jpg
[34] Liam Pozz liampozz. Circular Quay, Sydney, Australia. Creative Commons Zero, Public Domain Dedication. Accessed August 1, 2021 at https://commons.wikimedia.org/wiki/File:Ignitie_( Unsplash).jpg

[35] INSAR at Russian Wikipedia. First house built in the city of Norilsk, Russia. Public domain. Accessed August 1, 2021 at https://commons.wikimedia.org/wiki/File:Firsthous e.jpg

[36] Zac allan (talk). Nur-Sultan train station, Kazakhstan. Platform in the early morning. Public domain. Accessed August 1, 2021 at

https://commons.wikimedia.org/wiki/File:Astana_tr ain_station._Platform_in_the_early_morning.JPG

[37] Jan Fredrik Frantzen/Kommunikasjonssenteret UNN. Universitetssykehuset Nord-Norge HF, Breivika, Tromsø. Creative Commons Attribution 3.0. Accessed August 1, 2021 at https://upload.wikimedia.org/wikipedia/commons/ a/a9/Universitetssykehuset_tromso.jpg

[38] Patano. Estate al circolo polare.Creative Commons Attribution-Share Alike 3.0. Accessed August 1, 2021 at https://commons.wikimedia.org/wiki/File:Estate_al _circolo_polare_-_panoramio.jpg

[39] BlogDeBanderas. Aeropuerto Internacional de Ciudad del Cabo, Sudáfrica. Creative Commons AttributionShare Alike 4.0. Accessed August 1, 2021 at https://commons.wikimedia.org/wiki/File:2013.01. 03_Ciudad_del_Cabo,_ZA_(33).JPG

[40] Vyacheslav Argenberg. The India Gate (All India War Memorial. New Delhi, India. Creative Commons Attribution 4.0. Accessed August 1, 2021 at https://commons.wikimedia.org/wiki/File:Delhi,_In dia,_Rajpath_and_India_Gate.jpg

[41] Brendan Minish. Anadyr bus. Creative Commons Attribution 2.0. Accessed August 1, 2021 at https://commons.wikimedia.org/wiki/File:Anadyr_b us.jpg

[42] Akitoshi Seiyama. (2006). Virtual cooperativity in myoglobin oxygen saturation curve in skeletal muscle in vivo. Dynamic Medicine, 5, 3.

[43] Melvin Khee-Shing Leow. (2007). Configuration of the hemoglobin oxygen dissociation curve demystified: a basic mathematical proof for medical and biological sciences undergraduates. Adv Physiol Educ, 31, 198-201.

[44] Werner Müller-Esterl. (2008). Bioquímica. Fundamentos para Medicina y Ciencias de la Vida. Barcelona: Editorial Reverte.

[45] Atassi MZ, Childress C. (2005). Oxygen-binding heme complexes of peptides designed to mimic the heme environment of myoglobin and hemoglobin. Protein J, 24(1), 37-49.

[46] Tallarida RJ. (2016). Drug Combinations: Tests and Analysis with Isoboles. Curr Protoc Pharmacol, 72, 9-19.

[47] Doelle HW. (1982). Kinetic characteristics and regulatory mechanisms of glucokinase and fructokinase from Zymomonas mobilis. European J Appl Microbiol Biotechnol,14, 241-246. 
[48] Vickrey JF, Herve G, Evans DR. (2002). Pseudomonas aeruginosa Aspartate Transcarbamoylase. Characterization of its catalytic and regulatory properties. The journal of biological chemistry, 277(27), 24490-24498.

[49] Utzschneider KM, Prigeon RL, Carr DB, et al. (2006). Impact of Differences in Fasting Glucose and Glucose Tolerance on the Hyperbolic Relationship Between Insulin Sensitivity and Insulin Responses. Diabetes Car, 29, 356-362.

[50] Retnakaran R, Shen S, Hanley AJ, Vuksan V, Hamilton JK, Zinman B. (2008). Hyperbolic Relationship Between Insulin Secretion and Sensitivity on Oral Glucose Tolerance Test. Obesity, 16, 1901-1907.

[51] Mizuo J, Nakatsu T, Murakami T, et al. (2000). Exponential hyperbolic sine function fitting of heart rate response to constant load exercise. Jpn J Physiol, 50(4), 405-12.

[52] Seiryo Sugiura, Hiroshi Yamashita, Masataka Sata, et al. (1995). Force-velocity relations of rat cardiac myosin isozymes sliding on algal cell actin cables in vitro. Biochimica et Biophysics Acta, 1231, 69-75.
[53] Iwamoto H, Sugaya R, Sugi H. (1990). Force-velocity relation of frog skeletal muscle fibres shortening under continuously changing load. Journal of Physiology, 422, 185-202.

[54] Whinnery T, Forster EM, Rogers PB. (2014). The +Gz recovery of consciousness curve. Extreme Physiology \& Medicine, 3, 9.

[55] Zhou Y, Smith BH. Sharpee TO. (2018). Hyperbolic geometry of the olfactory space. Sci. Adv, 4(8), eaaq1458.

[56] Valey J.-P., Courtillot V. (1992). Las inversiones del campo magnético terrestre. Mundo científico, 12 (129), 938-951.

[57] Farina M., Lins de Barros H., Motta Esquivel D. (1990). Organismos magnetostáticos. Investigación y ciencia, diciembre, 70-78. 